\title{
Qualitative Phytochemical Analysis of Incarvillea emodi (Royle ex Lindl.) Chatterjee and Malva neglecta (Wallr.)
}

\author{
M. Huzafa*, Z. Jamal, A. Ahmed \\ Department of Botany, Government Post Graduate College, Abbottabad, Pakistan \\ *Corresponding author E-mail: muhammadhuzafa930696@gmail.com
}

Received: 02.08.2020. Accepted: 09.09.2020

\begin{abstract}
The present study was carried out to investigate the phytochemical profile of Incarvillea emodi and Malva neglecta. The two plants were screened for the presence of nine different classes of bioactive compounds. The qualitative tests were performed on the aerial and underground parts of the selected plants to relate the presence of phytochemicals with bioactivities of the plants. The selected plant material was extracted with three different solvents. These extracts were then subjected to phytochemical screening and the presence of various phytochemicals was confirmed by different standard confirmatory tests. Most of the phytochemicals were found to be present. Results showed that the underground parts of Incarvillea emodi contain comparatively greater number of phytochemicals than the aerial parts. Whereas, in case of Malva neglecta the aerial parts showed more positive results than the underground parts. The current study offers proof for the presence of important bioactive compounds in the studied plants and recommends isolation and characterization of these compounds in the future.
\end{abstract}

Keywords: Incarvillea emodi; Malva neglecta; Phytochemical screening; Bioactive compounds

\section{Introduction}

Historically, natural products derived from green inheritance (phytochemical) provide lead compounds in the development of new drugs all over the world (Pal and Shukla, 2003). An estimation by the World Health Organization (W.H.O.) suggests that nearly $80 \%$ of the population depends on natural sources for their prime medical need while the rest (20\%) of the population use integrated natural sources (Craag and Newman, 2001). The shortcomings of the drugs available today propel the discovery of new pharmacotherapeutic agents from medicinal plant research (Cordell, 1993). In order to promote the use of herbal medicines and for the determination of their potentials, the studies of medicinal plants should be more intensified especially those used as folk medicines (Ali, 2001; Nair "et al" 2005).

Incarvillea emodi (Royle ex Lindl.) Chatterjee is a wild herbaceous plant of genus Incarvillea and family Bignoniaceae found mainly at high altitudes of the western Himalayas. It is mainly distributed in India, Afghanistan, Nepal and Pakistan (Verma "et al"2008). It is locally known as Kaur (Ijaz "et al"2018). It prefers to grow in rock crevices and is sparsely found due to erosion of its natural habitat. It is listed as rare of Himalayan region (Singh and Sharma, 2006). Malva neglecta (Wallr.) is an annual herbaceous plant of the genus Malva and family Malvaceae growing to $0.6 \mathrm{~m}$. M. neglecta is native to almost all of Europe and is also found in China, Pakistan and India. It is traditionally eaten fresh as a leafy vegetable or used as decoctions. It is locally known as Sonchal (Rahim 'et al"2016) in Pakistan.

\section{Materials and Methods}

\section{Collection and identification of plant material}

I. emodi was collected from village Salhad-Abbottabad while M. neglecta was collected from Shimla Hills, Abbottabad district Abbottabad Khyber Pakhtunkhwa a Provine of Pakistan. The plants were collected in their flowering periods and from their wild habitat. The plants were identified from Flora of Pakistan (Nasir "et al"1972).

\section{Preparation of extracts}

After collection the plant material was thoroughly washed to remove soil particles. The plant material was air dried for approximately two months. Both plants were divided into two portions i.e., an aerial portion and an underground portion. After drying they were grounded to fine powder using an electric grinder. Extraction was done by maceration of powdered plant material in three different solvents: methanol, water and acetone. The powdered samples of plants (10 g each) were soaked in $100 \mathrm{ml}$ of solvent in an air tight stoppered bottle and were allowed to stand at room temperature for 72 hours with frequent agitation. The solvent soluble residue was filtered off by means of a muslin cloth followed by Whatman filter paper No. 1 . The extraction was repeated thrice. The samples were stored in a refrigerator at $4^{\circ} \mathrm{C}$ until used for further analysis.

Qualitative phytochemical analysis Phytochemical analysis was carried out by using the standard procedures described by (Sofowara 1993, Trease and Evans, 1989; Edeoga "et al"2005; Harborne, 1998) with some modifications. 


\section{Test for Carbohydrates (Molisch's test)}

In $2 \mathrm{ml}$ of plant sample extract, two drops of Molisch's reagent were added. The mixture was shaken well and few drops of concentrated Sulphuric acid were added slowly along the sides of test tube. A violet ring indicates the presence of carbohydrates.

\section{Tests for Proteins (Xanthoproteic test)}

The extracts were treated with few drops of concentrated Nitric acid. Formation of yellow colour indicates the presence of proteins .

\section{Tests for Alkaloids (Mayer's test and Wagner's Test)}

In a few $\mathrm{ml}$ of the filtrates, a drop of Mayer's reagent was added by the side of the test tube. A creamy or white precipitate indicates the test is positive. Few drops of Wagner's reagent are added to few $\mathrm{ml}$ of plant extract along the sides of test tube. A reddish- Brown precipitate confirms the test as positive.

\section{Tests for glycosides (Legal's test)}

Extracts were hydrolyzed with dilute hydrochloric acid, and then subjected to test for glycosides. Extracts were treated with sodium nitropruside in pyridine and sodium hydroxide. Formation of pink to blood red colour indicates the presence of cardiac glycosides.

\section{Test for saponins (Foam test)}

$0.5 \mathrm{gm}$ of extract was shaken with $2 \mathrm{ml}$ of water. If foam produced persists for ten minutes it indicates the presence of saponins.

\section{Test for Phenols (Ferric chloride test)}

Extracts were treated with 3-4 drops of $\mathrm{FeCl}_{3}$ solution. Formation of dark green color indicates the presence of phenols.

\section{Test for Flavonoids (Alkaline reagent test)}

Extracts were treated with few drops of sodium hydroxide solution. Formation of intense yellow colour, which becomes colorless on addition of dilute acid, indicates the presence of flavonoids.

\section{Tests for Tannins (Gelatin test)}

The extract was dissolved in $5 \mathrm{ml}$ of distilled water and $2 \mathrm{ml}$ of $1 \%$ solution of Gelatin containing $10 \% \mathrm{NaCl}$ was added to it. White precipitate indicates the presence of phenolic compounds.

\section{Polysteroids (Salkowski's test)}

Extracts were treated with chloroform and filtered. The filtrates were treated with few drops of Conc. Sulphuric acid, shaken and allowed to stand. Appearance of golden yellow colour indicates the presence of triterpenes.

\section{Results and Discussion}

We made the Phytochemical profiles of I. emodi and M. neglecta are shown in Tables 1 and 2. Most of the phytochemicals were classified as present or strongly present.

Table 1. Phytochemical profile of Incarvillea emodi.

\begin{tabular}{|c|c|c|c|c|c|c|c|}
\hline \multirow[t]{2}{*}{ Phytochemicals } & \multirow[t]{2}{*}{ Phytochemical tests } & \multicolumn{2}{|c|}{ Aerial Parts } & \multicolumn{4}{|c|}{ Underground Parts } \\
\hline & & Met & Aqu & Ace & Met & Aqu & Ace \\
\hline Carbohydrates & Molish's test & + & + & - & + & + & + \\
\hline Proteins & Xanthoproteic & ++ & ++ & ++ & ++ & ++ & ++ \\
\hline Polysterols & Salkowski's test & - & + & + & + & + & + \\
\hline \multirow[t]{2}{*}{ Alkaloids } & Mayer's test & + & + & ++ & ++ & + & ++ \\
\hline & Wagner's test & - & + & ++ & ++ & + & ++ \\
\hline Glycosides & Legal's test & ++ & ++ & ++ & ++ & ++ & ++ \\
\hline Saponins & Foam test & + & + & + & - & + & + \\
\hline Phenols & Ferric chloride test & + & + & + & + & - & + \\
\hline Flavonoids & Alkaline reagent test & ++ & ++ & - & ++ & ++ & ++ \\
\hline Tannins & Gelatin test & + & - & - & + & - & - \\
\hline
\end{tabular}

Met; Methanol, Aqu; Aqueous, Ace; Acetone, ++; strongly present, +; present, -; Absent

Table 2. Phytochemical profile of Malva neglecta.

\begin{tabular}{|c|c|c|c|c|c|c|c|}
\hline \multirow[t]{2}{*}{ Phytochemicals } & \multirow[t]{2}{*}{ Phytochemical tests } & \multicolumn{2}{|c|}{ Aerial Parts } & \multicolumn{4}{|c|}{ Underground Parts } \\
\hline & & Met & Aqu & Ace & Met & Aqu & Ace \\
\hline Carbohydrates & Molish's test & ++ & ++ & - & - & + & - \\
\hline Proteins & Xanthoproteic test & ++ & ++ & ++ & ++ & ++ & - \\
\hline Polysterols & Salkowski's test & + & + & - & + & + & + \\
\hline \multirow[t]{2}{*}{ Alkaloids } & Mayer's test & + & + & + & + & + & - \\
\hline & Wagner's test & - & - & - & - & - & - \\
\hline Glycosides & Legal's test & ++ & ++ & ++ & ++ & ++ & ++ \\
\hline Saponins & Foam test & - & - & + & + & + & + \\
\hline Phenols & Ferric chloride test & - & - & - & + & + & + \\
\hline Flavonoids & Alkaline reagent test & + & + & + & - & + & - \\
\hline Tannins & Gelatin test & + & + & + & + & - & - \\
\hline
\end{tabular}

Met; Methanol, Aqu; Aqueous, Ace; Acetone, ++; strongly present, +; present, -; absent 
The data showed higher alkaloids, proteins, glycosides and flavonoids contents in the underground parts of 1 . emodi compared with that of aerial parts. Similarly the underground parts of $M$. neglecta showed more positive results for phenolic contents when compared with the aerial parts.

Tannins were found to be absent in most of the extracts of $I$. emodi while proteins, flavonoids and various extracts of alkaloids revealed their strong presence. The present findings are in accordance with the previous studies. The studies carried out by Kapoor "et al" 1971 and Dinda "et al" 2002 involved the identification and isolation of different alkaloids from various parts of $I$. emodi. Several workers have reported the analgesic (Harborne, 1973), antispasmodic, cytotoxic (Nobori "et al" 1994) and antibacterial properties of alkaloids. Khan "et al" 2007 suggested that the anti-diabetic properties and anti-tumor activities of $I$. emodiare due to the presence of certain specific carbohydrates. Glycosides were also found to be present.

Extracts of aerial and underground parts of $M$. neglecta contain different phytochemicals in variable concentrations. These parts showed negative results for the presence of alkaloids with Wagner's test however they showed positive results with Mayer's test. Saponins and phenols were found to be absent in aerial parts of $M$. neglecta while the underground extracts showed negative results for flavonoids and tannins. However, previous studies reported the presence of phenols in the aerial parts as well (Hasimi 'et al" 2017). The methanol extracts of aerial and underground parts showed positive results for the presence of tannins while the remaining three solvents showed negative results. The slight difference in the findings of methanolic extracts offered a proof that solvents differ in their extracting capabilities due to differences in affinities for specific chemicals (Hayouni 'et al"2007).

\section{Conclusion}

Our results clearly demonstrate that the two plants contain high amounts of bioactive constituents. A comparison of the aerial and underground parts of the two plants was also made. It is therefore confirmed that the biological activities and medicinal properties exhibited by $I$. emodi and $M$. neglecta are by virtue of several bioactive constituents. We can potentailly validate the traditional use of these plants for the treatment of various diseases.

\section{Aknowlegments}

The authors are thankful to Department of Botany, Government Post Graduate College Abbottabad for providing research facilities to carry out this research work.

\section{References}

Ali, N. A., W. D Jülich, C. Kusnick and U. Lindequist. 2001. Screening of Yemeni medicinal plants for antibacterial and cytotoxic activities. Journal of Ethnopharmacology, 74 (2), 173-179.

Cordell, G. A. 1993. Pharmacognosy-new roots for an old science. Studies in natural products chemistry, 13, 629-629.

Cragg, G. M and J. D. Newman 2001. Natural product drug discovery in the next millennium. Pharmaceutical Biology, 39 (sup 1), 8-17.

Dinda, B and U. De. Chandra. 2002. 19-Epialstonine from Amphicome emodi roots.

Edeoga H.O., D. E. Okwu, B. O. Mbaebie, 2005. Phytochemical constituents of some Nigerian medicinal plants. African Journal of Biotechnology, 4, 685-688.

Harborne, A. J. 1998. Phytochemical methods a guide to modern techniques of plant analysis. Springer Science \& Business Media.

Hasimi, N., A. Ertaş, E. Varhan Oral, and H. Alkan. 2017. Chemical profile of Malva neglecta and Malvella sherardiana by LCMS/MS, GC/MS and their anticholinesterase, antimicrobial and antioxidant properties with aflatoxin-contents.

Hayouni, E. A., M. Abedrabba, M. Bouix, and M. Hamdi. 2007. The effects of solvents and extraction method on the phenolic contents and biological activities in vitro of Tunisian Quercus coccifera L. and Juniperus phoenicea L. fruit extracts. Food chemistry, 105 (3), 1126-1134.

Ijaz, F., Z. Iqbal, I. U. Rahman, J. Alam, S. M. Khan, G. M. Shah and A. Afzal. 2016. Investigation of traditional medicinal floral knowledge of Sarban Hills, Abbottabad, KP, $\begin{array}{lllllllll}\text { Pakistan. Journal of ethnopharmacology, 179, 208-233. } & & \\ \text { Kapoor, S. K., J. M. Kohli and A. Zaman. 1971. Amphicoside I. A new bitter glycoside from }\end{array}$ Amphicome emodi Lindl. Tetrahedron Letters, 12 (30), 2839-2840.

Khan, U., R. A. Qureshi, S. Saeed and A. D. Bond. 2007. An orthorhombic polymorph of myoinositol. Acta Crystallographica Section E: Structure Reports Online, 63 (2), 530-532.

Nair R., T. Kalariya and S. Chanda. 2005. Antibacterial activity of some selected Indian medicinal flora. Turk. J. Biol., 29: 4147.

Nasir, E., S. I. Ali and R. R. Stewart. 1972. Flora of West Pakistan.

Nobori, T., K. Miura, D. J. Wu, A. Lois, K. Takabayashi, and D. A Carson. 1994. Deletions of the cyclin-dependent kinase-4 inhibitor gene in multiple human cancers. Nature, 368 (6473), 753-756.

Pal, S. K., and Y. Shukla. 2003. Herbal medicine: current status and the future. Asian Pacific Journal of Cancer Prevention, 4 (4), 281-288.

Rahim, H., A. Sadiq, S. Khan, K. A. Chishti, F. Amin, M. A. Khan and S. Abbas. 2016. Isolation and preliminary evaluation of Malva neglecta mucilage: A novel tablet binder. Brazilian Journal of Pharmaceutical Sciences, 52 (1), 201-210.

Singh, H and M. Sharma. 2006. Flora of Chamba District (Himachal Pradesh). Bishen Singh and Mahindra Pal Singh Publishers, Dehradun.

Sofowora, A. 1993. Recent trends in research into African medicinal plants. Journal of Ethnopharmacology, 38 (2-3), $197-208$.

Trease, G. E and Evans W.C. Pharmacognosy, 11th end, brailliere tindall, London. 1989, pp. 45-50.

Verma, S., V. Kaul, R. Magotra and A. K. Koul. 2008. Pollinator-induced anther dehiscence in Incarvillea emodi (Bignoniaceae). Current Science, 94 (11), 1372-1374.

\section{Citation:}

Huzafa, M., Jamal, Z., Ahmed, A. (2020). Qualitative Phytochemical Analysis of Incarvillea emodi (Royle ex Lindl.) Chatterjee and Malva neglecta (Wallr.). Ukrainian Journal of Ecology, 10 (4), 93-95. 